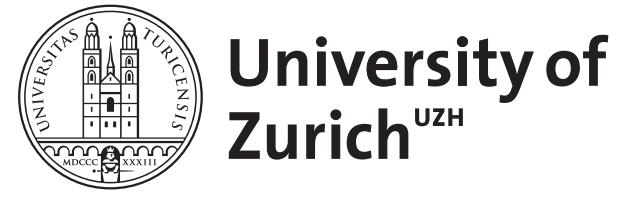

\title{
Souveränität und Globalisierung
}

\author{
Marti, Urs
}

Posted at the Zurich Open Repository and Archive, University of Zurich ZORA URL: https://doi.org/10.5167/uzh-80820

Book Section

Published Version

Originally published at:

Marti, Urs (2003). Souveränität und Globalisierung. In: Marti, Urs; Kohler, Georg. Konturen der neuen Welt(un)ordnung : Beiträge zu einer Theorie der normativen Prinzipien internationaler Politik. Berlin/New York: de Gruyter, 165-188. 


\title{
Souveränität und Globalisierung
}

\author{
Urs Marti
}

In Gegenwartsdiagnosen wird häufig das Ende der Souveränität konstatiert. Der Begriff der Souveränität ist vielschichtig, er wird in unterschiedlichen Kontexten verwendet und ruft gegensätzliche Assoziationen hervor. Souveränität ist eine soziale Institution, eine bestimmte Art und Weise der Ausübung und Verteilung von Macht. Als politische Organisationsform hat sie ihre Geschichte und die Frage nach der Zukunft souveräner Staaten ist sinnvoll. Souveränität ist überdies eine Hypothese, ein Modell zur Erklärung politisch-rechtlicher Ordnung, das kritisiert oder mittels der Konstruktion von Hilfshypothesen gegen Kritik immunisiert werden kann. Schließlich ist Souveränität ein normatives Prinzip, das eine Antwort auf die Frage nach den Kriterien legitimer Machtausübung gibt. Umstritten ist also nicht nur, ob der souveräne Staat in einem weltweit sich wandelnden Umfeld überleben kann, umstritten ist auch, welcher Erklärungswert der Souveränitätshypothese noch zukommt, und umstritten ist vor allem, ob das Prinzip der Souveränität weiterhin als legitim gelten kann. Sind souveräne Herrschaftsansprüche im Namen der Menschenrechte oder der Marktfreiheit zurückzuweisen, oder ist Souveränität ein Synonym für politische Handlungsfähigkeit, eine Voraussetzung von Selbstbestimmung und Demokratie?

Ich werde zunächst einige Sachverhalte unterscheiden, die mit dem Stichwort vom Ende der Souveränität bezeichnet werden. Die postmoderne Lesart, derzufolge dieses Ende nur im Kontext der Überwindung der Moderne angemessen zu begreifen ist, kritisiere ich im zweiten Abschnitt. Im dritten Abschnitt schlage ich vor, Souveränität unter dem Aspekt rationaler Machtorganisation zu analysieren. Dass ökonomische Akteure auf staatliche Souveränität angewiesen sind und sie zugleich zu unterlaufen suchen, ist Thema des vierten Abschnitts. Die mit der ökonomischen Globalisierung einhergehende Globalisierung von Recht und Politik gibt, so lautet die These des letzten Abschnitts, vorderhand keine überzeugenden Antworten auf die Frage, auf die das Souveränitätsprinzip bislang eine Antwort gegeben hat.

\section{Was heißt: Ende der Souveränität?}

Obgleich heute mit einer Vielfalt von Souveränitätsbegriffen gearbeitet wird, bleibt die klassische Definition unverzichtbar. Unter Souveränität wird ein Herrschaftsanspruch verstanden, der den Staat nach innen und außen konstituiert. Souveränität ist jedoch nicht mit unbeschränkter Handlungsfähigkeit oder willkürlicher 
Machtausübung gleichzusetzen, sondern bedeutet ein diesseits wie jenseits der territorialen Grenzen anerkanntes Recht. Innerhalb der Grenzen wird der Träger der Souveränität als höchste rechtliche Autorität anerkannt (innere Souveränität), außerhalb der Grenzen als freies und gleichberechtigtes, von jeder äußeren Autorität unabhängiges Subjekt politischen Handelns (äußere Souveränität). ${ }^{1}$ Von dieser Definition kann die Forschung ausgehen, muss sie jedoch im Hinblick auf die gewählte Perspektive präzisieren, erweitern oder modifizieren.

Für die Stelle des Trägers der Souveränität kommen verschiedene Kandidaten in Frage, und das Souveränitätsprinzip kann der Rechtfertigung unterschiedlicher politischer Ziele dienen. In der Frühzeit des Absolutismus drückt es den Selbstbehauptungswillen der monarchischen Staatsgewalt aus, entspricht aber auch den Interessen der frühbürgerlichen Gesellschaft. Die Staatsgewalt wird zur Einhaltung eines Vertrags verpflichtet, dessen Zweck im Schutz elementarer Rechte der Bürger besteht. Die logische Konsequenz dieser Umdeutung ist die Idee der Volkssouveränität. Seit dem 19. Jahrhundert berufen sich die in Europa entstehenden Nationalstaaten auf das Prinzip der Souveränität, rechtfertigen damit aber nicht selten eine aggressive und expansive Politik innerhalb wie außerhalb des Kontinents. Im 20. Jahrhundert dient es den kolonisierten Völkern zur Begründung ihrer Forderungen nach staatlicher und wirtschaftlicher Unabhängigkeit. Souveränität kann dynastischen oder demokratischen, revolutionären oder nationalistischen, imperialistischen oder anti-imperialistischen, hegemonialen oder emanzipatorischen Bestrebungen dienen, in jedem Fall aber artikuliert sich in der Berufung darauf der Wille zur politischen Unabhängigkeit.

Auch die völkerrechtliche Bedeutung von Souveränität unterliegt dem historischen Wandel. Als wichtigstes Datum, das den Beginn der Epoche des klassischen Völkerrechts markiert, gilt das Jahr 1648. Seit dem Westfälischen Frieden beruht das Völkerrechtssystem auf dem Prinzip einzelstaatlicher Souveränität. Staaten werden unter der Bedingung, dass sie gewisse Kriterien wie die Kontrolle über ihr Territorium und die Fähigkeit, Verträge abzuschließen und einzuhalten, erfüllen, als die einzigen legitimen Gemeinwesen anerkannt. Von ihnen wird erwartet, dass sie sich nicht in die Angelegenheiten anderer Staaten einmischen, ihnen steht aber auch das Recht zu, Kriege zu führen. Als Gemeinschaft von freien und gleichberechtigten Partnern beschränkt sich die Staatengemeinschaft allerdings bis zum ausgehenden 18. Jahrhundert vollständig und bis ins 20. Jahrhundert hinein weitgehend auf Europa. Erst 1960 wird mit der UNO-Resolution zur Entkolonisierung eine Globalisierung des Völkerrechts eingeleitet (Philpott, 1999, S. 160 ff).

In der zweiten Hälfte des 20. Jahrhunderts nimmt die Welt somit tatsächlich die Gestalt einer Gemeinschaft souveräner Staaten an. Allerdings verändert sich im Zuge des Umbruchs des Völkerrechts auch die Bedeutung der äußeren Souveränität. Gemäß moderner Auffassung anerkennen die Staaten die Normen des zwingenden Völkerrechts und verzichten freiwillig auf einen Teil ihrer Souveränität. An-

$1,[\ldots]$ the idea of sovereignty was the idea that there is a final an absolute political authority in the political community; [...] and no final and absolute authority exists elsewhere"; Hinsley, 1986, S. 26; vgl. Seidelmann, 1992; Philpott, 1997; 1999; Jackson; 1999a. Einen Eindruck von den vielfältigen Definitionsproblemen vermitteln Camilleri/Falk, 1992, S. 11-43. 
stelle des Rechts der Staaten, Krieg zu führen, tritt ein allgemeines Kriegs- und Gewaltverbot. Die Normen der Koexistenz werden ergänzt durch eine Verpflichtung zur Kooperation. Von den Staaten wird erwartet, dass sie zum Zweck der Förderung und Erhaltung des internationalen Friedens und der internationalen Sicherheit zusammenarbeiten und dabei gegebenenfalls auch sozial-, wirtschafts- und umweltpolitische Ziele gemeinsam unterstützen (Kimminich, 1997, S. 74-101). Die UNO-Charta bekräftigt den Grundsatz der souveränen Gleichheit aller Mitglieder (Art. 2), definiert aber auch die für die Herbeiführung friedlicher Beziehungen zwischen gleichberechtigten Nationen erforderlichen Voraussetzungen und setzt sich deren Förderung zum Ziel; darunter fällt die Achtung und Verwirklichung der Menschenrechte und Grundfreiheiten (Art. 1; 55). Angesichts der vor allem seit dem Ende des Kalten Krieges wachsenden globalpolitischen Verantwortung der UNO zeichnet sich ein neues Souveränitätsverständnis ab. Unter Souveränität ließe sich künftig ein Recht verstehen, in internationalen Angelegenheiten mitzuentscheiden und sich an der Lösung globalpolitischer Probleme zu beteiligen. Dieses Recht impliziert eine Verantwortung: Souveräne Staaten sind gegenüber der internationalen Gemeinschaft rechenschaftspflichtig (Taylor, 1999, S. 135-143).

Während die Neuinterpretation der äußeren Souveränität jüngeren Datums ist, beginnt jene der inneren Souveränität mit den demokratischen Revolutionen des ausgehenden 18. Jahrhunderts. Mit ihnen setzt ein Prozess der zunehmenden Bindung der Souveränität ein: Souveränität ist nicht die Gewalt, die, weil sie Recht schafft, über dem Recht steht, vielmehr kommt sie der Rechtsordnung zu, die über der Gesellschaft und ihren Interessengruppen steht. Im Urteil einiger Autoren steht das Souveränitätsprinzip allerdings in unversöhnlichem Gegensatz zum Verfassungsstaat und zu den Menschenrechten (Kriele, 1994). Dagegen wird argumentiert, moderne Volkssouveränität sei im Sinne eines Letztentscheidungsrechts unverzichtbare Legitimationsgrundlage des Staates (Abromeit, 1995, S. 50 ff). Häufig wird der Grundsatz vertreten, nur das Volk könne verfassunggebende Gewalt sein, doch müsse die Verfassung eine neue Gewalt schaffen, die nicht über ihr steht. Es stellt sich dann freilich die Frage, ob ein Zustand, worin das Volk als „pouvoir constituant“ schweigen muss, sobald es die Verfassung legitimiert hat, die Rechtsordnung („pouvoir constitué“) also beispielsweise nicht mehr nach Maßgabe von demokratisch ermittelten Gerechtigkeitskriterien reformiert werden kann, mit dem modernen Politikverständnis vereinbar ist (vgl. Böckenförde, 1991, S. 90-112).

Die Rechtsordnung beruht auf einem politischen Willen und einer politischen Macht; sie steht unter Reformdruck, sobald neue Ansprüche politisiert werden. Was Gegenstand der Gesetzgebung sein soll, wird in politischen Auseinandersetzungen entschieden, doch sind solche Entscheidungen nicht zwingend unwiderruflich. Gesellschaftliche und wirtschaftliche Veränderungen wie gegenwärtig die neoliberale Globalisierung stellen für Politik und Gesetzgebung neue Herausforderungen dar. Es stellt sich in diesem Kontext auch die Frage, ob die Unterscheidung zwischen innerer und äußerer Souveränität noch zeitgemäß ist. Unter innerer Souveränität wurde bislang die Fähigkeit der politischen Autorität verstanden, innerhalb territorialer Grenzen effektive Kontrolle auszuüben. Aber innere Souveränität hat offensichtlich einen Außenaspekt, zur Diskussion steht nämlich die Fähigkeit politischer 
Autoritäten, grenzüberschreitende Bewegungen von Menschen, Waren, Kapital, Information oder Schadstoffen zu kontrollieren. ${ }^{2}$ Ob der Begriff der Souveränität auch jene Kontroll-, Regulations- und Interventionsfähigkeit umfasst, die eine selbstbestimmte Wirtschafts- und Sozialpolitik erlaubt, bleibt allerdings umstritten. ${ }^{3}$

Souveränität ist eine rechtliche Institution, doch thematisieren viele Souveränitätstheorien implizit oder explizit auch Aspekte der Macht. Der Souveränitätsanspruch eines Staates kann selbst dann formell anerkannt werden, wenn ihm die Macht fehlt, innerhalb seiner Grenzen eine Rechtsordnung zu erhalten und international als gleichberechtigter Partner respektiert zu werden. Internationale Organisationen gehen von der im Widerspruch zu den faktischen Machtverhältnissen stehenden Hypothese gleichberechtigter, souveräner Nationalstaaten aus. Souveränität wird jedoch auch als organisierte Heuchelei definiert (Krasner, 1999). In realistischer Sichtweise entspricht die Verletzung völkerrechtlicher Normen der Logik internationaler Politik, da die Macht zwischen den Staaten ungleich verteilt und staatliches Handeln von egoistischen Motiven bestimmt ist. Großmächte wie die USA und die Sowjetunion haben Interventionsrechte geltend gemacht und die Souveränitätsrechte anderer Staaten massiv verletzt; internationale Finanzinstitutionen haben sich in die Politik ärmerer Staaten eingemischt. Wird das Faktum globaler Machtasymmetrie ins Zentrum der Analyse gestellt, muss Souveränität als ungeeignete Hypothese erscheinen. Tatsächlich haben in der Geschichte nur wenige Staaten alle Attribute der Souveränität - Territorium, Anerkennung, Autonomie und Kontrolle - besessen. Zwar wird argumentiert, der Begriff sei für die Analyse der europäischen Politik vom 17. bis zum 19. Jahrhundert hilfreich, doch ist $\mathrm{zu}$ bedenken, dass Nationalstaaten nie autarke Gemeinwesen, autonome und gleichmächtige Akteure der internationalen Politik gewesen sind.

Die Unterscheidung zwischen Recht und Macht, Autorität und Kontrolle ist sinnvoll; eine Souveränitätstheorie freilich, die den Aspekt der Macht ausblendet, dürfte für die historische, soziologische und politikwissenschaftliche Forschung von beschränktem Wert sein. Verliert ein Staat wegen der fehlenden Macht, bestimmte gesellschaftliche Kräfte zu kontrollieren, sein Gewaltmonopol, wird die Rede von seiner Souveränität selbst dann fragwürdig, wenn sein rechtlicher Status formell weiterhin anerkannt wird. Ebenso problematisch ist es, einen Staat, der aufgrund seiner wirtschaftlichen Lage seinen Verfassungsauftrag nicht mehr erfüllen kann, als souverän zu bezeichnen. Relevant ist auch die Frage, ob tatsächlich der verfassungsmäßig definierte Träger der Souveränität entscheidet oder ob andere Kräfte wie Parteien, wirtschaftliche oder religiöse Interessengruppen dies tun. Die Überprüfung der Souveränitätshypothese hat mithin einerseits zu klären, ob in den Rechtsquellen die Souveränität eines politischen Gemeinwesens bestätigt

2 Krasner, 1999, S. 9-25, unterscheidet zwischen „domestic sovereignty“ und „interdependence sovereignty“. Bezüglich der äußeren Souveränität unterscheidet er zwischen „Westphalian sovereignty“, d.h. dem Prinzip der Nicht-Intervention, und ,international legal sovereignty“, d.h. den Praktiken gegenseitiger Anerkennung zwischen rechtlich unabhängigen territorialen Einheiten.

3 Vgl. dazu Quiggin, 2001. Jackson, 1999a, S. 10, hält den Begriff der ökonomischen Souveränität dagegen für irreführend. 
wird, andererseits muss sie die Ebene der Macht einbeziehen und untersuchen, ob die effektiven Handlungsmöglichkeiten politischer Institutionen ihrem rechtlichen Status entsprechen.

Unter Souveränität wird mithin ein Rechtsanspruch verstanden, der die Gesetzgebung betrifft, aber ebenso die Fähigkeit, die Gesetze zu vollziehen, sowie die Bereitschaft der staatlichen Gewalt, für ihr Handeln die Verantwortung zu übernehmen. In welchem Sinn kann nun von einem Ende der Souveränität gesprochen werden? Beziehen sich entsprechende Diagnosen auf den rechtlichen Status oder auf die Macht von Staaten, auf die Legitimität des Souveränitätsanspruchs oder auf die Fähigkeit souveränen Handelns?

\subsection{Souveränität und Menschenrechte}

Gründet die Staatengemeinschaft normativ auf dem Prinzip staatlicher Souveränität, oder haben die universellen Menschenrechte im modernen Völkerrecht die Souveränität als Grundnorm verdrängt? Zweifellos ist die Menschenrechtsidee für das traditionelle Souveränitätsverständnis zu einer ernsthaften Herausforderung geworden. Die Ansicht, jede Politik müsse sich als Sachwalterin menschenrechtlicher Anliegen rechtfertigen, stößt trotz Disputen über kulturvariante Interpretationen der Menschenrechte weltweit auf wachsende Zustimmung. Der Menschenrechtsschutz ist in der Nachkriegszeit zu einer zentralen Aufgabe des Völkerrechts avanciert; der objektive Charakter von Menschenrechtsverträgen wird international anerkannt (Kälin, 1994). Die Staaten können Menschenrechte jedoch gemäß besonderen Traditionen und Interessen unterschiedlich interpretieren. Auf internationaler Ebene fehlt eine für die Durchsetzung der Menschenrechte zuständige exekutive und judikative Gewalt (Kimminich, 1997, S. 335-353).

Werden unter Menschenrechten vorstaatliche, den Menschen von Natur zukommende Rechte verstanden, müssen sie notwendig in Widerspruch geraten mit den Staaten, soweit diese den Anspruch erheben, über allen Normen zu stehen. Werden darunter jedoch positive Rechte und wird unter staatlicher Souveränität die Souveränität einer Verfassung verstanden, kann von einem grundlegenden Wertekonflikt nicht die Rede sein. Souveränität ist eine Form der Machtausübung und kann als solche missbraucht werden. Rechte können aber im Ernstfall nur garantiert werden, wenn eine mit Zwangsbefugnis ausgestattete Staatsgewalt existiert. Staatliche Souveränität und individuelle Freiheitswünsche begrenzen sich gegenseitig; zwar wird die Grenzziehung immer umstritten bleiben, sie resultiert jedoch nicht aus dem Aufeinanderprallen unvereinbarer Ansprüche, vielmehr ist die Begrenzung der Freiheit Bedingung ihrer Möglichkeit. Wenn nur jene Einschränkung der Freiheit als rechtmäßig gilt, deren Zweck die Freiheit selbst ist, besteht zwischen Menschenrechten und Souveränität kein antinomisches Verhältnis.

Die von demokratischen Verfassungsstaaten beanspruchte Souveränität ist nicht mit uneingeschränkter Hoheitsgewalt gleichzusetzen, sondern mit einer Staatsgewalt, die ihre Grenzen an individuellen Grundrechten findet (Schaber, 1996, S. 7683), diese aber auch gegen Angriffe verteidigt, die von gesellschaftlichen und ökonomischen Kräften ausgehen. Volkssouveränität ist eine institutionelle Vorausset- 
zung des Menschenrechtsschutzes, ${ }^{4}$ es ist sogar denkbar, dass sich demokratische Staaten darauf einigen, die Aufgabe einer übernationalen Gewalt zu übertragen. Allerdings ist fraglich, ob der Menschenrechtsidee eine hinreichend klare Konzeption zugrunde liegt, die im Konfliktfall als allseits anerkanntes normatives Entscheidungskriterium dienen könnte. Die Menschenrechte waren im Kalten Krieg ein Spielball der internationalen Politik und sind es nach dessen Ende geblieben. Die Bestimmung ihres Kernbereichs und die Festsetzung der Rangordnung ihrer Dimensionen erweist sich als heikles Unterfangen. Der Grund dafür ist nicht primär die kulturelle Pluralität von Rechts- und Pflichtauffassungen, wie dies von kulturrelativistischer Seite unterstellt wird. Theoretische Kontroversen widerspiegeln politische Auseinandersetzungen, nicht nur zwischen Staaten mit unterschiedlichen politischen Systemen, sondern auch innerhalb liberal-demokratischer Gesellschaften. Das Recht auf Privateigentum lässt sich gemäß westlicher Rechtstradition so gut als Menschenrecht postulieren wie das Recht auf Subsistenz und soziale Sicherheit. Daraus lassen sich dann wiederum ein Recht auf unbeschränkte Handels- und Investitionsfreiheit oder ein Recht auf staatliche Selbstbestimmung im wirtschaftlichen Bereich und soziale Teilhabe ableiten. Solche Ansprüche geraten notwendig miteinander in Widerspruch.

Ist Souveränität, verstanden als Mittel zum Zweck der Durchsetzung des gesellschaftlichen Friedens mittels Errichtung einer Ordnung, die Menschen elementare Rechte gewährt, selbst Gegenstand eines menschenrechtlichen Anspruchs? Mit den Revolutionen von 1776 und 1789 wird die Idee der Menschenrechte zur Legitimationsgrundlage der Politik. In der Nachkriegszeit macht die Situation der Staatenlosen jedoch deutlich, wie paradox der Begriff eines dem Menschen schlechthin, ungeachtet seiner Zugehörigkeit zu einer politischen Gemeinschaft zustehenden Rechtes ist. Arendt spricht von einem Recht, Rechte zu haben, das grundlegender ist als jedes Menschenrecht (Arendt, 1986, S. 452-470). Ein solches Recht lässt sich als Recht auf politische Inklusion definieren, somit lässt sich ein Recht auf Einbezug in ein souveränes, handlungsfähiges politisches Gemeinwesen postulieren. Verstanden als Durchsetzungsmacht ist Souveränität eine notwendige, wenn auch keine hinreichende Bedingung einer menschenrechtskonformen Ordnung. Staaten können ihre Verantwortung als Adressaten von Rechtsansprüchen nicht wahrnehmen, oder sie können die Macht, Rechte effektiv zu schützen, verlieren. In beiden Fällen stellt sich die Frage, ob nicht eine andere Durchsetzungsmacht Menschenrechte schützen soll, Sanktionen oder Interventionen gegen Staaten, die Menschenrechte verletzen, ${ }^{5}$ also unter gewissen Bedingungen als legitim gelten können.

\subsection{Der Funktionsverlust des Staates}

Die Transformation von Staatlichkeit stößt in historischen und sozialwissenschaftlichen Untersuchungen auf wachsende Aufmerksamkeit. Der Staat wird als soziale

4 Zur Auffassung, wonach sich Souveränität und Menschenrechte gegenseitig bedingen: Habermas, 1992, S. 122-135; Brunkhorst, 1999.

5 Vgl. zur aktuellen Debatte Zanetti, 1998; Maus, 1998; Maus, 1999. 
Institution verstanden, die sich vor einigen Jahrhunderten herausgebildet hat, in der Folgezeit eine Reihe von für die Gesellschaft vitalen Funktion übernimmt und gegenwärtig einem tiefgreifenden funktionalen Wandel unterliegt (Kuhlmann, 2000). Zuweilen wird sogar ihr Niedergang prognostiziert (Creveld, 1999). Im Folgenden möchte ich stichwortartig einige Aspekte dieser Transformation erwähnen.

- Im Hinblick auf die Ansprüche an die staatliche Steuerungsfähigkeit wird seit einiger Zeit bereits mehr Bescheidenheit empfohlen. Die Möglichkeiten des Staates, die Sabotage seiner Steuerungsbemühungen seitens mächtiger nicht-staatlicher Akteure zu verhindern, nehmen ab. Doch nicht nur die Fähigkeit, auch die Berechtigung von Staat und Politik, gesellschaftliche und wirtschaftliche Prozesse zu steuern, wird zunehmend in Frage gestellt. Seit dem ausgehenden 17. Jahrhundert ist im liberalen Staatsverständnis die Idee einer weitgehenden Respektierung der zivilgesellschaftlichen Autonomie zwar bereits angelegt. Zeitgenössische neoliberale oder libertäre Forderungen tendieren aber dazu, dem demokratischen Sozialstaat die Legitimität grundsätzlich abzusprechen. Der Beweis, dass eine von jeder staatlichen Regelung befreite Zivilgesellschaft imstande ist, eine nicht-diskriminierende, für alle Betroffenen zumutbare Rechtsordnung aufrechtzuerhalten, ist freilich nie erbracht worden. Überdies sprechen politikwissenschaftliche Untersuchungen dafür, dass Deregulierungen längerfristig durch Reregulierungen kompensiert werden. Entscheidend ist in diesem Kontext die Frage, inwiefern der „Rückzug des Staates“, der Abbau staatlicher Steuerung, wie er etwa in der Privatisierung öffentlicher Dienste und in der Reduktion staatlicher Leistungen für soziale Sicherheitssysteme zum Ausdruck kommt, negative Auswirkungen auf die Stabilität politischer Gemeinwesen hat und die Revision bislang anerkannter Gerechtigkeitsmaßstäbe erzwingt. Dass die „Entzauberung“ von Recht und Staat in normativer Hinsicht Probleme schafft, deren Lösung noch kaum absehbar ist, wird auch von Autoren eingeräumt, die überzeugt sind, der demokratische Staat und das positive Recht seien als gesellschaftliche Steuerungsinstrumente an die Grenzen ihrer Leistungsfähigkeit gelangt. Gefragt wird, wie der Rückfall in Formen der Gesellschaftssteuerung, die den normativen Standards der Moderne widersprechen, vermieden werden kann, und unter welchen Voraussetzungen künftig eine Selbsteinwirkung der Gesellschaft möglich sein wird? ${ }^{6}$

- Staaten scheinen ihre Handlungsfähigkeit im wirtschafts- und sozialpolitischen Bereich zu verlieren, weil sich die Märkte ihrer Kontrolle entziehen. Private Akteure, in erster Linie transnational tätige Konzerne, können die staatliche Gesetzgebung massiv beeinflussen, den Gesetzesvollzug sabotieren, die Ausgaben- und Umverteilungspolitik von Staaten diktieren und deren soziale Stabilität gefährden, kurz: jeden Versuch autonomer, demokratisch legitimierter Selbstgesetzgebung unterlaufen (Mahnkopf, 1998). Die Macht dazu besitzen sie, weil sie global mobil sind und das Verhalten von Staaten sanktionieren können. Allerdings wird auch geltend gemacht, dass sie die Macht nur dank der Unterstützung besitzen, die ihnen einzelne Staaten zukommen lassen. Transnationale Unternehmen können für Staaten zu Legitimationsquellen werden; sie übernehmen die Verantwortung für die Sicherung

6 Vgl. dazu Habermas, 1992; Willke, 1998. 
der sozio-ökonomischen Entwicklung, was bedingt, dass die Staaten öffentliche Ressourcen in den privatwirtschaftlichen Sektor transferieren und eine den Bedürfnissen der Unternehmen angepasste Gesetzgebung garantieren (Petrella, 1996). Exemplarisch ist an die WTO zu erinnern; in ihren Entscheidungen spiegeln sich häufig die Interessen global tätiger Unternehmen wider, die freilich auf staatliche Fürsprache angewiesen sind. Wenn Marktteilnehmer heute global so agieren können, wie sie es tun, dann deshalb, weil die Staaten mitspielen, indem sie sich gegeneinander ausspielen lassen anstatt zu kooperieren. Der Wettbewerb der zu Standorten degradierten Staaten funktioniert nicht nur, weil Staaten Standortvorteile schaffen und anbieten, die der Nachfrage seitens transnationaler Korporationen entsprechen, sondern auch, weil die nachfragende Seite auf zuverlässige Standort-Angebote angewiesen ist, deren Qualität nur von funktionierenden rechtlich-politischen Organisationen verbürgt werden kann. Überspitzt gesagt lässt sich von einem Angebot von und einer Nachfrage nach Souveränität sprechen. ${ }^{7}$ Zwar kann gerade für arme Staaten der Standortwettbewerb zu einem dramatischen Verlust wirtschaftspolitischer Autonomie führen, sie sogar zur „freiwilligen“ Abtretung der Souveränität über einen Teil des Territoriums durch die Schaffung von Freihandels- und Exportproduktionszonen bewegen. Die Fähigkeit privater Akteure, Staaten in ihrer Handlungsfreiheit einzuschränken, verdankt sich jedoch nicht selten der Unterstützung durch eine Staatsmacht, die sich der Schaffung effizienter Kontroll- und Interventionsinstrumente auf Weltebene gerade unter Berufung auf ihre Souveränität entgegenstellt.

Die Nachfrage multinationaler Unternehmen nach Souveränität bezieht sich vor allem auf den Schutz von Verträgen und Eigentumsrechten. Kann diese Souveränitätsfunktion auch von supranationalen Institutionen erfüllt werden (Sassen, 1996, S. 1-30)? Gewiss ist, dass die Herausbildung eines transnationalen Wirtschaftsrechts für die nationalstaatliche Souveränität eine Herausforderung darstellt. Nationales Recht, das die Wirtschaft reguliert, steht heute zunehmend im Konkurrenzverhältnis zu neuen, globalen Rechtsnormen, die Handel und Investition zwischen Nationen regeln. Die Staaten sind nicht mehr die einzigen Rechtsquellen und müssen in bestimmten Fällen den Anspruch, für die Rechtsdurchsetzung innerhalb ihres Territoriums alleine zuständig zu sein, zurücknehmen. In den Bereichen des Wirtschafts- und Handelsrechts bilden sich globale Normen heraus, die weniger das Produkt politisch-institutioneller Entscheidungen denn sozioökonomischer Prozesse sind. Diese als „proto-law“ oder „soft law" bezeichneten Normen, die häufig die Interessen globaler Akteure widerspiegeln, sind nicht als verbindliches "hard law" anerkannt, und die sie erzeugenden Institutionen leiden unter einem erheblichen Demokratiedefizit (Scheuerman, 2001).

- In seiner Existenz bedroht ist der Staat, wenn er das Gewaltmonopol verliert. Die sicherheitspolitischen Probleme haben sich auf nationaler und internationaler Ebene verschärft, neue Bedrohungsszenarien sind entstanden (Kaldor, 1998; Held/ McGrew/Goldblatt/Perraton, 1999, S. 87-148). Die Auswirkungen dieser Verän-

7 Vgl. in diesem Zusammenhang Keohane, 2000, S. 117: „Sovereignty is less a territorially defined barrier than a bargaining resource for a politics characterized by complex transnational networks." 
derungen auf die Souveränität einzelner Staaten sind unterschiedlich. Bedroht ist sie in armen Ländern, in denen bewaffnete Bürgerkriegsparteien oder private Streitkräfte Teile des Territoriums besetzen, kriminelle Organisationen oder private Unternehmen die Macht unter sich aufzuteilen suchen. In solchen Fällen wird von einem Scheitern des Staates gesprochen, wobei fraglich ist, ob die betreffenden Staaten je als souverän haben gelten können (Clapham, 1999). In der Regel handelt es sich um Schöpfungen des von europäischen Staaten errichteten Kolonialsystems. Unabhängig geworden, haben sich diese Staaten auf ihre Souveränität berufen und seit den 70er Jahren erfolglos ökonomische Souveränität beansprucht. ${ }^{8}$ Häufig sind sie trotz der formellen Anerkennung ihrer Souveränität nicht fähig, autonom zu agieren. Aufgrund einer langen Geschichte der Fremdbestimmung wie aufgrund des fehlenden Willens, moderne, demokratische Institutionen aufzubauen, sind sie den Zugriffen anderer Staaten mehr oder weniger ohnmächtig ausgeliefert. Ihre ökonomische Souveränität wird häufig durch die Strukturanpassungsprogramme des Internationalen Währungsfonds verletzt.

Die vielfältigen Bedrohungen militärischer, ökonomischer, sozialer und ökologischer Art, denen die Welt der Gegenwart ausgesetzt ist, können Staaten dazu motivieren, ihre Souveränitätsansprüche zu überdenken. Sie können aber auch zu einer Zementierung asymmetrischer Machtverhältnisse führen. Während vor allem schwache Staaten den Bedrohungen nicht gewachsen sind, können starke Staaten unter Berufung auf Souveränitätsrechte und nationale Interessen internationale Vereinbarungen sabotieren und derart Lösungen, die der Bedrohungslage adäquat wären, verhindern. ${ }^{9}$

- Können die Probleme, die sich der gegenwärtigen Politik stellen, von den Einzelstaaten selbst innerhalb ihres Territoriums nicht mehr bewältigt werden, artikulieren sich Bedürfnisse nach übernationalen politischen Ordnungseinheiten. Sollen die neuen institutionellen Formen regionaler Integration die Gestalt eines föderalen Staates und nicht bloß einer Staatenföderation annehmen, dann setzt ihr Aufbau bei den Nationalstaaten die Bereitschaft zu einem zumindest partiellen Souveränitätsverzicht voraus. Von besonderem Interesse ist in diesem Kontext die Europäische Union. Ob es sich dabei um einen Bundesstaat oder einen Staatenbund handelt oder handeln soll, ist umstritten. Denkbar ist die Entstehung eines europäischen Staates, der die souveränen Kompetenzen und Verpflichtungen von den alten Staaten übernimmt und die klassischen Bedingungen der Souveränität erfüllt. Denkbar ist ebenso ein System gestufter oder geteilter Souveränität, worin Europa beispielsweise für die Wirtschafts- und Sozialpolitik zuständig wäre. Kompetenzkonflikte wären in einem solchen arbeitsteiligen System wohl unausweichlich. Wirtschaftspolitische Entscheidungen, die auf europäischer Ebene gefällt werden, können Auswirkungen auf die Sicherheitspolitik der Einzelstaaten

8 Ihren Niederschlag haben solche Anliegen 1974 in der UNO-Charta der wirtschaftlichen Rechte und Pflichten der Staaten sowie im Programm zur Errichtung einer neuen Weltwirtschaftsordnung gefunden.

9 Exemplarisch ist die US-amerikanische Haltung zum Internationalen Strafgerichtshof, zum Klimaschutzprotokoll, zum Atomwaffentestverbot, zur Kleinwaffenkontrolle oder zum Kontrollregime für das Verbot biologischer Waffen. 
haben. In einem komplizierten, auf mehrere Ebenen verteilten System von Regierung und "governance“ bleibt oft unklar, wer für eine bestimmte Politik verantwortlich ist. Unklar bleibt auch, wie Volkssouveränität zu konzipieren ist. Die wirtschaftliche Integration ist zu einem guten Teil unter dem Druck demokratisch nicht ermächtigter Lobbies zustande gekommen; die neoliberale Ausrichtung der Politik der europäischen Kommission entspricht keinem klar definierten Auftrag der betroffenen Bevölkerung. Grundlegende Probleme materialer und prozeduraler Legitimität, die der Prozess europäischer Staatsbildung und Verfassunggebung stellt, bleiben ungelöst (Oeter, 1998; Wallace, 1999).

- Die Ansicht, bestimmte Aufgaben wie die Friedenssicherung und der Schutz der natürlichen Lebensgrundlagen, für die die Staaten bisher zuständig gewesen sind, könnten nur noch global gelöst werden, stößt heute auf breite Zustimmung. Bezweifelt wird aber nicht nur, ob die Staaten fähig sind, solche Aufgaben im Alleingang zu lösen, bezweifelt wird ebenso, ob sie auch dann das Recht haben, ihre für diese Bereiche relevante Politik als innere Angelegenheiten zu behandeln, wenn deren Auswirkungen zur Benachteiligung der Bevölkerungen anderer Staaten führen können. Im Prinzip beruht heute auch die einzelstaatliche Politik auf der Überzeugung, bestimmte Aufgaben seien nur im Rahmen der internationalen Kooperation zu lösen und müssten auf eine Weise gelöst werden, die für die Bevölkerungen aller betroffenen Staaten zumutbar ist. Erfahrungsgemäß widerspiegeln kollektive Entscheidungen allerdings häufig eher die Interessen hegemonialer Mächte als einen freiwilligen Konsens zwischen gleichberechtigten Staaten.

In diesem Kontext stellt sich schließlich die Frage, inwiefern der Souveränitätsverlust der Staaten durch die Entfaltung von "global governance“ kompensiert werden kann. „Governance“ meint, anders als „government", die Gesamtheit sozialer Ordnungssysteme. Mit dem Begriff wird angedeutet, dass auch dann, wenn Staaten ihre Regierungsfähigkeit verlieren, die von ihnen bislang erledigten Aufgaben nicht zwingend ungelöst bleiben (Rosenau, 1992a, S. 3-9). „Global governance“ lässt sich begreifen als die Erledigung dringender Regierungsaufgaben, die sich auf Weltebene stellen, wobei diese Tätigkeit nicht die Erfüllung eines gesetzgeberischen Auftrags, sondern eher eine technokratische Tätigkeit ist. Als solche kann sie ihren Sinn haben, allerdings vermag sie keine Regeln zu bestimmen, wie in einer Welt der ungleichen Machtverteilung mit Interessenkollisionen umzugehen ist (Altvater/ Mahnkopf, 1999, S. 509-516). Es fehlt eine Opposition, eine verfassungsmäßig geregelte Gewaltenteilung, im weitesten Sinn ein Mechanismus des Machtausgleichs (Strange, 1996, S. 198). Kritiker des 1995 von der „Commission on Global Governance“ veröffentlichten Berichts „Our Global Neighborhood“ machen geltend, es sei widersinnig, „global governance“ zu loben, ohne sich ernsthaft mit der Möglichkeit von „global government“ auseinanderzusetzen (Harris/Yunker, 1999).

\subsection{Abschließende Bemerkungen}

Als Kompetenz-Kompetenz, das heißt als Kompetenz einer Person oder einer Institution, die eigene Kompetenz selbst zu bestimmen, bezeichnet der Souveränitätsbegriff einen Herrschaftsanspruch. Dieser Anspruch ist aber von seiner 
Zweckbezogenheit nicht zu lösen: Macht darf nur im Interesse der ihr Unterworfenen ausgeübt werden. Im Laufe der letzten Jahrhunderte ist die Zweckbestimmung präzisiert worden. Souveräne Gesetzgebung und Herrschaft muss legitim sein; sie muss Leben, Sicherheit, Freiheit und Eigentum der Mitglieder des Gemeinwesens schützen, sie muss schließlich für einen sozialen Ausgleich sorgen und elementare soziale Bedürfnisse als Rechtsansprüche anerkennen. Obgleich Souveränität bisher fast ausschließlich Nationalstaaten zugekommen ist, ist denkbar, dass sie als Zuschreibung bestimmter Kompetenzen und Verpflichtungen auch nicht- oder überstaatlichen Institutionen zukommt. Staatliche Souveränität hat sich in den letzten Jahrhunderten mehrmals verändert und wird sich auch künftig verändern, sie wird aber nicht einfach verschwinden, ohne dass an ihre Stelle andere Institutionen und Praktiken treten werden, die ihre Funktionen übernehmen. Eine bestimmte Form souveräner Handhabung von Macht wird wohl in jeder modernen Gesellschaft notwendige Voraussetzung für die Existenz einer stabilen und berechenbaren wie auch einer gerechten und kollektiv gestaltbaren Ordnung sein.

\section{Die postmoderne Kritik}

Die Krise der Souveränität wird von einigen Autoren als ein Ereignis gedeutet, das die Metaphysik der Subjektivität und damit jede Ethik, die das autonome Subjekt des liberalen Humanismus voraussetzt, praktisch widerlegt. Ideen wie Souveränität und Selbstgesetzgebung gelten in postmoderner Lesart entweder generell als Ausdruck rationalistischer Selbstüberschätzung, oder es wird argumentiert, der Universalismus der Aufklärung lasse sich auf globalisierte Verhältnisse nicht anwenden, da die abstrakte Gleichheitsidee nur im territorialen Rahmen realisierbar sei (Richter, 1992; Campbell/Dillon, 1993; Albert, 1996). Eine differenziertere Variante postmoderner Souveränitätskritik stellt die disziplinäre Trennung zwischen einer Theorie der Politik und einer Theorie der internationalen Beziehungen in Frage. Herkömmliche Theorien der Politik sehen in der staatlichen Souveränität die Grundbedingung politischen Lebens. Mit der Unterscheidung von Innen- und Außenraum schaffen sie eine Wertehierarchie zwischen einem Bereich des Eigenen, der geordneten Gemeinschaft, der Vernunft, des Berechenbaren und Normalen sowie einem Bereich des Anderen und Fremden, der Anarchie, der Unvernunft, der Barbarei und des Pathologischen. Auf politischer Ebene entspricht dieser Hierarchisierung ein Anspruch auf Exklusivität: Errungenschaften der Moderne wie Demokratie und universalistische Ethik bleiben Privilegien des Innenbereichs. Die Kritik zielt auf die Dekonstruktion normativ aufgeladener Begriffsoppositionen. Sie macht geltend, Theorien internationaler Beziehungen seien als analytische Instrumente unzuverlässig, da sie selbst bloßer Ausdruck gegenwärtiger Weltpolitik seien (Walker, 1993).

Foucaults Werk, insbesondere seine These von der unauflöslichen Verknüpfung von Macht und Wissen, hat zahlreiche Arbeiten im Umfeld der postmodernen Theorie der internationalen Beziehungen inspiriert (Devetak, 1996, S. 180-188). Archäologien oder Genealogien der Souveränität nehmen im Anschluss an Fou- 
caults Periodisierung epistemologischer Formationen eine Periodisierung der Souveränitätsdiskurse vor. Die Analyse der diese determinierenden epistemologischen Strukturen führt zum Schluss, das Souveränitätskonzept verdanke seine Intelligibilität jener epistemologischen Ordnung der Moderne, die laut Foucault den Menschen als ein Objekt wissenschaftlicher Erkenntnis zum souveränen Subjekt jeder möglichen Erkenntnis hat avancieren lassen; so wie im Zuge der epistemologischen Umwälzungen der Gegenwart der Mensch Foucaults Prognose gemäß verschwinden wird (Foucault, 1966), muss die Souveränität als ein die politische Realität gestaltendes und ihre Erkennbarkeit ermöglichendes Prinzip verschwinden (Bartelson, 1995).

Wenn Wahrheit, woran postmoderne Autorinnen und Autoren unter Berufung auf Foucault erinnern, bloß Effekt der Macht ist, können Theorien der internationalen Politik nur im Kontext von Machtstrategien verstanden werden. Dies muss freilich auch für postmoderne Theorien gelten; wenn das zu dekonstruierende Souveränitätsprinzip in jener modernen politischen Vorstellungskraft verwurzelt ist, die der Möglichkeit radikaler Kritik enge Grenzen zieht, bleibt unklar, worin ihre Aufgabe besteht. Offensichtlich zielt die dekonstruktive Methode nicht auf die Kritik oder Falsifikation einer Theorie, sondern auf die Offenlegung und damit Erschütterung ihrer Grundlagen, auf die Rekonstruktion der Geltungsbedingungen ihrer Prämissen. Ähnlich wie Walker hat Ashley die Opposition von nationaler Souveränität und internationaler Politik als Resultat diskursiver Ausschlussverfahren analysiert. Das Ergebnis der Dekonstruktion ist die Entdeckung des souveränen Menschen, der als Willenssubjekt und Bedürfniswesen dem modernen souveränen Staat als Legitimationsquelle dient. Dieser Mensch fühlt sich freilich gerade wegen seiner Souveränität nicht mehr an jene eingegrenzten Räume gebunden, die das Konzept nationalstaatlicher Souveränität voraussetzt. Unter Modernität scheint Ashley im Anschluss an Foucault eine sowohl praktische wie epistemologische Disposition zu verstehen, die der Souveränität der menschlichen Vernunft und des menschlichen Handelns Vorrang einräumt. Das Prinzip staatlicher Souveränität kann in diesem Sinn nur als abgeleitetes verstanden werden: Souveränität kann dem Staat ausschließlich dann zukommen, wenn sein Legitimitätsanspruch auf den freien und öffentlichen Vernunftgebrauch der Menschen zurückgeführt werden kann (Ashley, 1995).

Foucaults eigenes Werk enthält eine Kritik des Souveränitätsprinzips, die allerdings nicht systematisch entfaltet wird. Souveränität ist darin ein Schlüsselbegriff für das Verständnis der Funktion humanistischer Diskurse; indem sie eine bedingte Freiheit verspricht, dient sie auf perfide Weise der Unterdrückung des spontanen individuellen Willens zur Macht. Der Mensch wird mit Rechten ausgestattet, die er nur beanspruchen kann, wenn er sich dem Gesetz unterwirft. Die Institutionalisierung einer unparteiischen Judikative stellt in Foucaults Sicht im Vergleich zum germanischen Rechtssystem keinen Fortschritt dar. Die Individuen verlieren das Recht, aufgrund allseits anerkannter Regeln ihre Streitigkeiten selbst beizulegen und werden gezwungen, sich einer politisch-judikativen Macht zu unterwerfen. In dieser Keimform staatlicher Souveränität erblickt Foucault eine diabolische Erfindung (Foucault, 1994 II, S. 226 f; 570-588). Im Zuge der Entfaltung 
disziplinärer Macht kommt dem Souveränitätsprinzip jedoch nur noch eine ideologische Funktion zu: Sie verspricht dem Individuum souveräne Rechte und begründet eine Demokratisierung der Machtverhältnisse, die sich angesichts des untergründigen disziplinären Zwangs als illusionär erweist (Foucault, 1994 III, S. 177-189). Foucaults Kritik der demokratischen Souveränität weist Affinitäten zu jener konservativen Kulturkritik auf, die Macht primär als Effekt des zentralisierenden und nivellierenden demokratischen Staats thematisiert. Wenn er indes geltend macht, die Souveränität des modernen Individuums sei keine echte Souveränität, dann prangert er staatliche Souveränität im Namen eben jener Idee individueller Souveränität als unzumutbare Machtanmaßung an, auf der die moderne Auffassung legitimer Souveränität beruht.

\section{Die Ökonomie der Macht}

Die Idee der Souveränität gibt eine Antwort auf die Frage nach der Möglichkeit politischen Handelns und der wünschbaren Gestaltung der Machtbeziehungen. ${ }^{10}$ Ursprünglich ist diese Antwort motiviert von der Erfahrung, dass die unübersichtliche Machtverteilung und die Existenz konkurrierender Machtzentren, wie sie die Feudalordnung kennzeichnen, den Bestand eines Gemeinwesens gefährden. Souveränität zielt auf die zumindest partielle Entmachtung bislang mächtiger gesellschaftlicher Kräfte, sie ist Mittel zum Zweck einer nach Möglichkeit rationalen Organisation und Verteilung von Macht. Machtverhältnisse sind so zu gestalten, dass gesellschaftliche Konflikte besser kontrollier- und berechenbar werden. Gewalt soll gezielt eingesetzt werden, um das durch diese Konflikte freigesetzte Gewaltpotential eindämmen zu können. In diesem Sinne lässt sich von einer Ökonomie der Macht sprechen, von einem nach Maßgabe der Sicherheits-, Freiheits- und Wohlfahrtsbedürfnisse der Bevölkerung sparsamen und doch effizienten Einsatz von Macht.

Seit dem ausgehenden Mittelalter bezeichnet das Wort „souverain“ in Frankreich, später auch in England, die Kompetenz eines Herrschers, in einem Rechtsstreit endgültig zu entscheiden. Erst im Zuge der Entscheidung im Kompetenzenstreit zwischen Kirche und Staat erhält der Souveränitätsbegriff die Bedeutung einer Kompetenz, die eigenen Kompetenzen selbst zu wählen und auszufüllen (Quaritsch, 1986, S. 36). Die Herausbildung des neuzeitlichen Souveränitätsprinzips ist vor dem Hintergrund des Aufstiegs des absolutistischen Staates zu verstehen. Es dient der Legitimation einer in der Hand des Monarchen konzentrierten, territorial eingegrenzten Staatsgewalt. Souveräne Herrschaft erscheint im 16. Jahr-

10 Hinsley, 1986, S. 1: „[...] sovereignty is not a fact. It is a concept which men in certain circumstances have applied - a quality they have attributed or a claim they have counterposed - to the political power which they or other men were exercising.“ Camilleri/Falk, 1992, S. 11: „[...] sovereignty $[\ldots]$ is part of the more general discourse of power whose function is not only to describe political and economic arrangements but to explain and justify them as if they belonged to the natural order of things." Walker, 1993, S. 64: „[...] the principle of state sovereignty $[\ldots]$ is a very powerful, even elegant answer to the deeply provocative question as to how political life is possible at all." 
hundert einigen französischen Juristen und Politikern als das einzige Mittel, die im Zuge der konfessionellen Bürgerkriege zerstörte gesellschaftliche Ordnung wieder aufzubauen und ihr Stabilität zu verleihen. Ihnen zufolge ist die Aufspaltung der Herrschaft auf mehrere ständisch oder religiös legitimierte Träger die hauptsächliche Ursache der desolaten Verfassung ihres Landes. Weil insbesondere der Kompetenzenstreit zwischen kirchlichen und weltlichen Mächten ein gewaltiges Konfliktpotential enthält, muss der Staat die Kompetenz, die eigene Kompetenz zu bestimmen, gegen kirchliche Kompetenzansprüche durchsetzen. Solche Einsichten führen zu einer für die spätere Entwicklung wegweisenden Säkularisierung des staatstheoretischen Denkens. „Les politiques“ werden im 16. Jahrhundert die Mitglieder einer Gruppe französischer Gelehrter genannt, die den Ausweg aus dem für das Land ruinösen Bürgerkrieg in der Entpolitisierung der Religion erblicken. Der primäre Zweck politischen Handelns besteht in ihrer Sicht in der Herstellung und Sicherung von Ordnung und Frieden mittels Ausgleich, Toleranz und Gleichbehandlung der Bürger.

Im historischen Rückblick erscheint die Machtkonzentration beim monarchischen Staat als entscheidender Faktor, der die langfristigen Prozesse der Säkularisierung, des Abbaus von Privilegien und der zunehmenden Rechtsgleichheit der Untertanen gefördert hat. Der dem Kreis der „politiques“ zugerechnete Jean Bodin definiert Souveränität als die dem Staat zukommende absolute, hinsichtlich Machtbefugnis, Aufgabenstellung und Dauer unbegrenzte Gewalt. Dem Träger der Souveränität wird die Befehlsgewalt bedingungslos übertragen. Souveränität meint jedoch nicht willkürliche Herrschaft; der souveräne Fürst steht zwar über dem positiven Gesetz; er ist als Gesetzgeber nicht an die von seinen Vorgängern oder von ihm selbst erlassenen Gesetze gebunden, wohl aber, wie Bodin betont, den Gesetzen Gottes und der Natur unterworfen. Konkret heißt das: Er kann allen Untertanen ohne deren Zustimmung Gesetze auferlegen, ihnen jedoch nicht nach Belieben Abgaben auferlegen und ihr Eigentum antasten. Souveränität wird als eine im Interesse der Erhaltung des Gemeinwesens, der Respektierung seines Ansehens und der Verfolgung seiner Vorteile notwendig unbeschränkte Gewalt begriffen, die für die Erreichung dieser Zwecke Regeln definiert, die Zwecke selbst aber nicht in Frage stellen darf (Bodin, 1981; Klippel, 1990, S. 107-110). In frühen Souveränitätskonzeptionen ist zwar ein Widerstandsrecht der Untertanen nicht vorgesehen, da dieses mit den negativen Erfahrungen der konfessionellen Bürgerkriege assoziiert wird, es werden aber Kriterien definiert, die verhindern sollen, dass Souveränität zum Vorwand willkürlicher Machtausübung wird. Elementare Ansprüche der Gesellschaft an die Rechtsordnung wie jener auf die Einhaltung von Verträgen und auf das Verbot willkürlicher Besteuerung werden in den Rang eines Naturrechts und eines göttlichen Gesetzes erhoben.

Die Bestimmung des dem Gemeinwesen zuträglichen Ausmaßes der Freiheit der Untertanen ist indes abhängig von der Einschätzung der ihm drohenden Gefahren. Thomas Hobbes geht in seiner vertragstheoretischen Begründung der Souveränität vom Gedankenexperiment eines anarchisch-kriegerischen Naturzustands aus. Dessen Logik entsprechend ist das absolute staatliche Machtmonopol unverzichtbare Bedingung der Herstellung und Bewahrung des gesellschaftlichen Frie- 
dens. Von Natur aus sind Menschen Wesen, deren Handeln von einem nie zu befriedigenden Verlangen nach Macht bestimmt ist und die daher untereinander notwendig zu Konkurrenten und Feinden werden. Diese Konkurrenz, die für sie zur tödlichen Bedrohung wird, kann nur überwunden werden, wenn sie ihre Macht dem Souverän abtreten, der sich im Gegenzug dazu verpflichtet, ihr Leben und ihre vernünftigen Rechtsansprüche zu schützen sowie für ihre Sicherheit und ihren Wohlstand zu sorgen. Im Bild, das Hobbes vom Naturzustand zeichnet, widerspiegelt sich die Erfahrung des Bürgerkriegs. Dem Souverän müssen alle Kompetenzen übertragen werden, die er benötigt, um den Rückfall in den Bürgerkrieg zu verhindern. Seine Rechte sind unübertragbar und unteilbar; schon die Idee geteilter Souveränität vermag den Bürgerkrieg auszulösen. Als Souverän ist er dem Gesetz nicht unterworfen. Er kann freilich nicht alle Handlungen regeln; in jenen Bereichen, in denen eine vertragliche Rechtsübertragung unmöglich ist, bleiben die Menschen frei, das zu tun, was ihnen beliebt. Nicht übertragbar ist das Recht auf Leben und Selbsterhaltung. Dagegen gilt das Recht auf Privateigentum nur bedingt; das übergeordnete Prinzip der Staatserhaltung kann seine Einschränkung erfordern (Hobbes, 1984).

In der frühliberalen Neuformulierung des Souveränitätsprinzips kommt dem Privateigentum bei der Definition der Legitimitätskriterien des Staats dagegen eine dominierende Rolle zu. John Locke definiert politische Gewalt als ein Recht, für die Regelung und Erhaltung des Eigentums Gesetze zu schaffen und notfalls unter Androhung der Todesstrafe durchzusetzen. Das hauptsächliche Ziel, das die Menschen mit ihrem Eintritt in ein politisches Gemeinwesen verfolgen, ist für Locke der friedliche und sichere Genuss ihres Eigentums. Die Erreichung dieses Ziels setzt eine Gewalt voraus, die in Streitfällen ein unparteiisches Urteil zu sprechen und zu vollstrecken vermag. Sie fehlt zwar im Naturzustand, dennoch sind die Menschen darin frei und besitzen Eigentum. Dem Privateigentum kommt ein naturrechtlicher Status zu; weil sein Genuss im Naturzustand möglich ist, kann dessen bloße Überwindung politische Macht nicht hinreichend legitimieren. Die Verpflichtung, Leben, Freiheit und Eigentum der Menschen zu achten und zu schützen, begrenzt ihre Reichweite und begründet ihre Legitimität (Locke, 1977).

Die absolutistische wie die konstitutionalistische Variante der Souveränitätslehre zielen auf eine rationalere Organisation der Macht. ${ }^{11}$ In beiden Konzeptionen steht der Naturzustand für einen unvernünftigen, weil den Streit perpetuierenden Umgang mit Macht. In beiden Konzeptionen verschafft jedoch die bloße Monopolisierung der Macht dem Staat noch keine Legitimität. Indem die potentiellen Vertragspartner sich wechselseitig verpflichten, auf Gewalt zu verzichten, ermächtigen sie den Souverän, über die Einhaltung dieser gegenseitigen Versprechen zu wachen. Alle Mitglieder des politischen Gemeinwesens haben den gleichen Anspruch auf Rechtsschutz, das heißt auf die Ausübung staatlicher Macht zwecks Abwendung oder Sanktionierung der sie bedrohenden Gewalt. In diesem Sinne

11 Rousseau, 1964, S. 177, hat im zweiten „Discours“ die andere Seite dieser Ökonomie beleuchtet: die Reichen verstehen es, mittels der Staatsgründung ihre Gegner für ihren eigenen Schutz arbeiten zu lassen. 
lässt sich von einer egalitären Machtverteilung sprechen. Erst das Prinzip der Rechtsgleichheit verschafft dem Staat seine Legitimitätsbasis. Dabei handelt es sich zwar um ein normatives Prinzip; faktisch hat aber die souveräne Macht des neuzeitlichen Staats immerhin eine breitere Machtverteilung bewirkt. Dem staatlichen Gewaltmonopol ist zu verdanken, dass die sozialen Verhältnisse für die Menschen sicherer werden. Staatliche Gewalt kann sich zwar gegen die Bevölkerung oder Teile davon wenden, indem jedoch der Staat ein System einklagbarer Rechte errichtet, schafft er eine Gegenmacht, die seine Möglichkeiten, Macht willkürlich auszuüben, einschränkt (Giddens, 1985, S. 172-221). Das entscheidende Merkmal moderner Staaten ist Michael Mann zufolge die kollektive infrastrukturelle Macht. ${ }^{12}$ Recht und Verwaltung durchdringen die Gesellschaft, aber umgekehrt durchdringt auch die Gesellschaft den Staat; die Ausbreitung der Macht bewirkt, dass Machtmittel und Kontrollmöglichkeiten für einen wachsenden Teil der Bevölkerung verfügbar werden.

\section{Die Macht der Ökonomie}

Die Anerkennung staatlicher Souveränität gründet historisch weder auf der $\mathrm{Zu}$ stimmung aller betroffenen Individuen noch auf dem Willen, die gleichen Rechtsansprüche aller Mitglieder des Gemeinwesens zu verteidigen. Der neuzeitliche Staat entsteht in Klassengesellschaften und verteidigt primär die Rechtsansprüche bestimmter sozialer Klassen, wobei sich in diesen Ansprüchen vorwiegend ökonomische Interessen artikulieren. ${ }^{13}$ Mithin ist nicht nur die Ökonomie der Macht, sondern auch die Macht der Ökonomie zu analysieren, das heißt der Einfluss, den ökonomische Ideen wie organisierte ökonomische Interessen auf Politik und Gesetzgebung ausüben können. Hobbes' Souveränitätskonzeption und Lockes Liberalismus liegt, wie Macpherson gezeigt hat, eine besitzindividualistische Auffassung zugrunde: Die Gesellschaft setzt sich aus freien und gleichen Individuen zusammen, die als Eigentümer ihrer Fähigkeiten und der mittels deren Anwendung erworbenen Güter zueinander in Beziehung treten; der Staat dient dem Zweck, Eigentum zu schützen und geordnete Tauschbeziehungen aufrechtzuerhalten. Macht ist ein Gut, das auf dem Markt getauscht wird; der Wert der machtbesitzenden Individuen wird durch die Gesetze von Angebot und Nachfrage bestimmt. Hobbes' Naturzustand handelt, so Macphersons Argument, nicht von natürlichen Menschen, sondern von Menschen, deren Motive und Bedürfnisse durch eine bestimmte ökonomisch-soziale Ordnung geprägt sind; er müsste not-

12 „Infrastrukturelle Macht ist das institutionelle Vermögen eines Zentralstaates, ob despotisch oder nicht, sein Hoheitsgebiet zu durchdringen und politische Entscheidungen logistisch zu implementieren. Das ist kollektive Macht, gesellschaftlich ,vermittelte Macht', die das soziale Leben vermittels staatlicher Infrastrukturen koordiniert. [...] Infrastrukturelle Macht ist keine Einbahnstrasse, deren alleiniger Nutzer der Staat ist; auch die Parteien der Zivilgesellschaft profitieren von ihr, denn sie ermöglicht ihnen, den Staat ihrerseits zu kontrollieren [...].“ Mann, 1998, S. 78.

13 Zum Zusammenhang zwischen der Konzentration politischer Macht und dem Ausbau eines das Privateigentum garantierenden Rechtssystems vgl. Anderson, 1979, S. 27-52. 
wendig eintreten, würde diese Ordnung nicht durch die Staatsgewalt gebändigt. Es ist somit die durch die Konkurrenz egoistischer Individuen in ihrem Bestand bedrohte Eigentumsmarktgesellschaft, die auf eine zentralisierte souveräne Macht angewiesen ist. Für die Individuen ist es rational, sich diesem Souverän zu verpflichten, weil dadurch die Konkurrenzverhältnisse für sie berechenbar werden. ${ }^{14}$

Die Monopolisierung der Macht und die Institutionalisierung eines Rechtssystems dienen also nicht nur dem generellen Zweck der Zivilisierung, sondern, wie schon Neumann gezeigt hat, dem spezifischen Zweck, Austauschprozesse in der Konkurrenzgesellschaft berechenbar und vorhersehbar zu machen. Das Rechtssystem wirkt zwar egalisierend, verschleiert aber zugleich die wirklichen Verhältnisse der Ungleichheit; es verspricht allen Menschen Vorteile, die nur bestimmte soziale Gruppen nutzen können. Der Begriff der ökonomischen Freiheit impliziert eine Beschränkung des staatlichen Interventionsrechts in die Wirtschaft, die aus gesamtgesellschaftlicher Sicht nicht zwingend wünschbar ist. Die Zusicherung der Vertrags- und Handelsfreiheit ändert nichts an der realen Unfreiheit jener Mitglieder der Gesellschaft, die nicht über Produktionsmittel verfügen. Vertragstheorien können in ihrer Abstraktheit allerdings sowohl der Legitimation des Staates wie der Delegitimation staatlicher Intervention dienen, und die Anerkennung von Freiheits- und Gleichheitsforderungen in einem Bereich führt erfahrungsgemäß dazu, dass entsprechende Forderungen in anderen Bereichen erhoben werden (Neumann, 1980).

Der moderne Staat ist, so die Formulierung von Neumann, ein Kind der Warenproduktion. Bereits für Marx war klar, dass die Souveräne den wirtschaftlichen Verhältnissen nicht das Gesetz diktieren können, sondern sich ihnen fügen müssen (Marx MEW 4, S. 109). Allerdings vermochte nur die souveräne Macht jene stabilen Verhältnisse zu garantieren, innerhalb derer sich die kapitalistische Produktion entwickeln und kapitalistische Märkte etablieren konnten. Der nicht-interventionistische liberale Staat ist notwendig ein starker Staat, der nicht nur die bestehende Marktordnung schützt, sondern auch neue Märkte erobert und verteidigt (Neumann, 1980, S. 226 f). Zwischen einer bestimmten Organisation der politischen Macht und der rechtlichen Institutionen sowie einer bestimmten Produktionsund Zirkulationsweise besteht somit ein Zusammenhang. Auf die Analogie zwischen dem exklusiven Souveränitätsprinzip und dem ebenfalls exklusiven Recht auf Privateigentum, dessen Schutz im Zuge der Ablösung der Feudalordnung durch die absolutistische Monarchie zu einer primären Staatsaufgabe avanciert, ist schon mehrmals hingewiesen worden (Ruggie, 1986). Während das Recht auf Privateigentum andere Menschen vom Genuss eines bestimmten Gutes ausschließt, erhebt das Prinzip nationalstaatlicher Souveränität innerhalb territorialer Grenzen einen exklusiven politisch-juristischen Autoritätsanspruch. Angesichts dieser Analogie lässt sich die historische Funktion des souveränen Nationalstaats genauer bestimmen, aber auch dessen künftige Bedeutung in einer entgrenzten und zugleich auf den Schutz von Eigentumsrechten angewiesenen Ökonomie abschätzen.

14 Macpherson, 1973, besonders 15; 30-61; 113-118. Hobbes, 1984, Kap. 10. Habermas, 1992, S. $62 \mathrm{ff}$. 
Es stellt sich die Frage, ob Staaten, die im Alleingang oder im Verbund mit anderen Staaten ökonomische Freiheiten im Namen demokratischer, sozialpolitischer, menschenrechtlicher oder ökologischer Forderungen beschneiden, damit jenen historisch gewachsenen normativen Konsens aufs Spiel setzen, dem sie ihre Existenzberechtigung verdanken. Wenn umgekehrt den Staaten die wirtschaftspolitische Kontroll- und Interventionsbefugnis im Namen der ökonomischen Freiheit abgesprochen wird und deren Nutznießer bereit sind, den Staaten die Legitimationsgrundlage zu entziehen, so ist weiter zu fragen, ob die Nutznießer so handeln, weil sie von einer nicht-souveränen, aber dennoch rechtsschützenden Ordnung einen höheren Nutzen erwarten oder ob sie ihre langfristigen Nutzenmaximierungschancen falsch einschätzen.

Die Ansprüche der Kapitaleigner haben in der Gesetzgebung moderner Nationalstaaten ihren Niederschlag gefunden, andere gesellschaftliche Akteure haben die Gesetzgebung jedoch zunehmend mitgestaltet. Die Staaten haben nicht nur der kapitalistischen Produktion und Marktwirtschaft einen rechtlichen Rahmen verschafft, sie haben im Laufe der letzten zwei Jahrhunderte ebenfalls auf Herausforderungen wie die Demokratisierung und die Politisierung antagonistischer Klasseninteressen reagiert. Wenn die Reaktion auf diese Prozesse nicht nur in der Verschärfung staatlicher Repression und der Delegitimierung neuer Rechtsansprüche, sondern auch in einer auf Integration, Ausgleich und Privilegienabbau zielenden Politik bestanden hat, so lässt sich eine solche Politik aus Souveränitäts- und Sozialvertragstheorien herleiten. Diese können zwar der Verschleierung der unfriedlichen Koexistenz unterschiedlich freier Klassen dienen und den Staatsbürgerstatus ausschließlich den wirtschaftlich selbständigen Männern zugestehen, die ihnen zugrundliegende Logik enthält jedoch radikale Implikationen. Sie gründen auf der Einsicht, dass gesellschaftliche Verhältnisse auf Dauer nicht stabilisiert und pazifiziert werden können, wenn einer Mehrheit der darin sich artikulierenden Interessen die Legitimität abgesprochen wird. Von vernünftigen und autonomen Individuen ist die Zustimmung zu einer bestimmten Organisation der Gesellschaft nur dann zu erwarten, wenn sie die Gewissheit haben, dass sie in der gesellschaftlichen Kooperation nicht bloß die Lasten zu tragen haben und vom Nutzen ausgeschlossen bleiben. Sobald sie die Macht haben, die politische Ordnung in Frage zu stellen, können auch unterprivilegierte Klassen ihre Anerkennung als potentielle Vertragspartner erzwingen.

Der sozialstaatliche Ausbau der Demokratie bedingt eine intakte staatliche Kontroll- und Interventionsfähigkeit, einen Handlungsspielraum, der im Zuge der neoliberalen Globalisierung geschrumpft ist, während gleichzeitig die vom Sozialstaat zu bewältigenden Aufgaben gewachsen sind. Die Krise der Souveränität ist auch auf normativer Ebene zu analysieren; sie resultiert aus jenem Dilemma, in das Staaten unweigerlich geraten, wenn sie die Kriterien legitimen Handelns festsetzen. Historisch gesehen gehört sowohl das Versprechen der Verteidigung exklusiver Eigentumsrechte wie jenes der gerechten Verteilung von Nutzen und Lasten der sozialen Kooperation zu ihrer Legitimationsbasis; die Verteilungskämpfe der Gegenwart zeigen die Unmöglichkeit, beiden Aufgaben gerecht zu werden. Im Sinne der demokratischen Souveränitätsidee muss der Abbau sozialstaatlicher Leistungen, wie 
er im großen Ausmaß durch die vom Internationalen Währungsfonds südlichen und östlichen Ländern verordneten Strukturanpassungsprogramme, in geringerem Ausmaß durch die von Anleger- und Unternehmerseite von westlichen Ländern geforderte Austeritätspolitik erzwungen wird, als Vertragsbruch erscheinen. Der Staat als vertragsbrüchige Partei kann zwar auf seine Ohnmacht angesichts wirtschaftlicher Sachzwänge verweisen, was im Fall der mächtigen Industriestaaten aber kaum zu überzeugen vermag. Wenn die Staaten in ihrer Wirtschafts- und Sozialpolitik erpressbar geworden sind, dann auch darum, weil sie einzelnen wirtschaftlichen Akteuren das „Recht“ zugestanden haben, private und öffentliche Interessen gleichzusetzen. Denkbar ist aber auch, dass sich die Regierungen auf ihre sozialpolitische Verantwortung zurückbesinnen und die Intitiative im Rahmen internationaler Koordination zurückgewinnen. Für welche Rangordnung konkurrierender Rechtsansprüche sie sich entscheiden werden, ob Demokratie im Namen der Handels- und Investitionsfreiheit weiter begrenzt wird oder ob mächtige „global players" in die politische Verantwortung eingebunden werden, ist ungewiss. Hinsichtlich der durch die ökonomische Globalisierung bewirkten Transformation staatlicher Politik sind indes drei Aspekte zu unterscheiden.

- Der Rückzug der Staaten und die wachsende Macht der Märkte (Strange, 1996) lassen nicht zwingend auf eine generelle Schwächung staatlicher Politik schließen. Angesichts der Tatsache, dass die meisten multinationalen Unternehmen von ihren Heimatstaaten abhängig bleiben, dass die ärmeren Staaten von der neuen Weltwirtschaft wenig profitieren und dass die mächtigen Industriestaaten ihre Kontroll- und Regulierungsfähigkeit nicht eingebüßt haben, beurteilen einige Autoren Globalisierungstheorien skeptisch (Hirst/Thompson, 1996). Zwar fehlt heute oft der politische Wille, staatliche Macht zum Zweck einer stabileren und gerechteren Weltwirtschaftsordnung einzusetzen, private Akteure können ihre Interessen langfristig aber nur durchsetzen, wenn es ihnen gelingt, die nationale und internationale Politik für ihre Zwecke zu instrumentalisieren. Die Ansicht, ein von politischen Interventionen freies, ausschließlich von Marktmechanismen gesteuertes ökonomisches System sei wünschbar und realisierbar, ist ideologisch. Polanyis während des Zweiten Weltkriegs formulierte These, die Idee eines selbstregulierenden Marktes sei utopisch, wird durch neuere Studien bestätigt. Als zu erwartende Folgen ungenügender Marktregulierung werden anhaltende Arbeitslosigkeit, wiederkehrende Finanzkrisen, wachsende Ungleichheiten, fehlende Investitionen im Bildungs- und Forschungsbereich sowie die asymmetrische Verteilung von Wissen und Macht genannt. Die Marktutopie steht unter dem Verdacht, die humanen Kosten der von ihr postulierten Ordnung zu ignorieren, und der modernen Politik wird als hauptsächliches Verdienst weniger die Zivilisierung der Gewalt als die Zähmung der für die Menschen bedrohlichen Anarchie der Märkte zugutegehalten (Polanyi, 1978; Boyer, 1996; Willke, 2001).

- Die Diagnose einer Misere der Politik (Narr/Schubert, 1994) ist dennoch nicht falsch; eine einseitig die Ansprüche mächtiger wirtschaftlicher Akteure verteidigende Politik setzt ihre demokratische Legitimation aus Spiel. Eine funktionierende Demokratie ist auf einen sozialen Ausgleich angewiesen, der staatliche Umverteilung voraussetzt. Der Nationalstaat wird heute oft als institutionelle Bedingung der 
Möglichkeit demokratischer Verfahren, politischer Partizipation und sozialer Sicherheit verstanden, Globalisierung dagegen als Prozess, worin politisch folgenreiche Entscheidungen zunehmend von „unverfassten“ Mächten getroffen werden, von internationalen Organisationen, die sie keinem Wahlvolk gegenüber zu verantworten haben, über keinen verfassungsmäßigen Auftrag verfügen und dennoch der Welt eine ökonomische Verfassung zu geben trachten. Angesichts der Imperative von Deregulierung, Privatisierung und Standortwettbewerb ist Politik versucht, die Wahlfreiheit der Bürgerinnen und Bürger auf den Konsumbereich einzugrenzen. Fehlen angesichts ökonomischer Sachzwänge Handlungsalternativen, drohen demokratische Prozeduren zu bloßen Ritualen zu werden (Altvater/Mahnkopf, 1999). Zwar trifft zu, dass nationale Deregulierungen teilweise durch globale Reregulierungen kompensiert werden, allerdings resultieren sie häufig nicht aus der freiwilligen Zustimmung aller betroffenen Parteien, sondern widerspiegeln eher die Interessen mächtiger nationaler oder globaler Akteure. Transnationale Unternehmen können ihre Forderungen darin eher durchsetzen als etwa Gewerkschaften. Beispielsweise ist das Abkommen über handelsrelevante Aspekte geistiger Eigentumsrechte (TRIPs) aufgrund massiven Drucks von Unternehmen und der Androhung von Handelssanktionen gegen den Willen vieler ärmerer Länder zustandegekommen, während die Staaten in der Ratifizierung von Abkommen der Internationalen Arbeitsorganisation (ILO) zurückhaltend sind (Drahos/Braithwaite, 2001).

- Die durch die neoliberale Globalisierung erzwungene Machtverlagerung und Umverteilung von Wohlstand kann in vielen, insbesondere ärmeren Ländern Krisen und anarchische Zustände provozieren und jenen Staaten, die nicht mehr fähig sind, ihre Bürgerinnen und Bürger vor den bedrohlichen Wirkungen der Märkte zu beschützen, die Legitimationsbasis entziehen. Der Neoliberalismus hat sich bislang nicht als fähig erwiesen, ein konsensfähiges politisches Projekt zu definieren. Umso mehr rufen seine Forderungen und Strategien bei den davon Betroffenen Reaktionen hervor. Weltweit formieren sich neue politische Bewegungen, die der gegenwärtigen Globalisierungspolitik eine teils radikale, freilich auch von höchst unterschiedlichen, ja widersprüchlichen Anliegen motivierte Opposition entgegensetzen. $\mathrm{Ob}$ sie innerhalb der weltpolitischen Konstellation künftig größeres Gewicht erlangen können, hängt davon ab, ob sie ihre Anstrengungen ihrerseits global koordinieren und ein kohärentes politisches Programm entwerfen können. Bedürfnisse nach alternativer Politik sind vorhanden, und die Suche danach wird auch von der Einsicht ausgehen müssen, dass Fragen nach einer rationalen, stabilitätssichernden und nach Möglichkeit gerechten Machtverteilung heute nicht nur auf nationaler, sondern auch auf globaler Ebene neu beantwortet werden müssen (Brodie, 1996).

\section{Republikanische Souveränität}

Im Zeitalter seiner Gefährdung ist der Nationalstaat zur Projektionsfläche von Hoffnungen geworden, denen bei aller Gegensätzlichkeit ein Hang zur Idealisierung gemeinsam ist. Häufig wird die begriffliche Unterscheidung zwischen Souveränität, 
Staat, Nation, Volk, Gemeinschaft und kultureller Identität vernachlässigt (O’Neill, 1998); Spekulationen über ein menschliches Bedürfnis nach Grenzen müssen als Erklärungsgrund für die angebliche Notwendigkeit der Erhaltung abgegrenzter Nationen herhalten (Kersting, 1998, S. 61 f). Den Staaten wird die Funktion zugeschrieben, soziale Solidarität zu garantieren und eine kollektive Lebensform, eine eigene Kultur zu ermöglichen (Koller, 1996). Die verfassungsmäßige Aufgabe moderner Demokratien besteht jedoch primär in der Garantie gleicher Rechte für sämtliche Staatsbürgerinnen und Staatsbürger ungeachtet ihrer kulturellen Zugehörigkeit. Was die soziale Solidarität betrifft, so hat die Entwicklung der letzten Jahrzehnte ihre Grundlage sicher nicht gefestigt. Soziale Gerechtigkeit verdankt sich nicht primär emotionalen, innerhalb nationaler Gemeinschaften verfügbaren Ressourcen, sondern der stets bedrohten wirtschaftspolitischen Autonomie der Staaten.

Bisherige Versuche, das Prinzip demokratischer Selbstgesetzgebung umzusetzen, beschränken sich auf nationalstaatlich verfasste Gesellschaften. Das Unbehagen angesichts der Globalisierung erklärt sich auch aus der Befürchtung, diese werde eine für Demokratien fatale Neuverteilung der Macht provozieren: Während sich die Macht politischer Exekutivgewalten verselbständigt, kann sich der Wille des demokratischen Gesetzgebers nicht mehr artikulieren. Das entstaatlichte Weltrecht ist nicht demokratisch legitimiert, für einen großen Teil der Bevölkerung meist nicht einklagbar und erzwingbar, und überdies als Ausdruck der Interessen mächtiger Akteure auch nicht fähig, Ungleichheit erzeugende gesellschaftliche Verhältnisse zu zivilisieren (Brunkhorst, 1997). Im sich wandelnden Völkerechtsverständnis spielt heute „soft law“ eine wachsende Rolle. Der Begriff bezeichnet Rechtsnormen, die zwar als wesentliche Bestandteile des Völkerrechts verstanden werden, die aber keine unbedingte Geltung beanspruchen können und denen keine effizienten Sanktionsmechanismen entsprechen; es ist gleichsam ein Recht ohne Staat (Teubner, 1997). Die klassische Definition von Recht als sanktionsbewehrter Norm (Austin, 1955) mag für das Völkerrecht nur noch bedingt brauchbar sein. Recht kann schon auf nationaler Ebene nicht erfasst werden mit einer Definition, die einzig den Aspekt der zwangsbewehrten Norm hervorhebt. Der Prozess der Zivilisation durch Verrechtlichung ist deshalb erfolgreich gewesen, weil sich die Respektierung von Rechten nie allein der steten Präsenz einer Zwangsgewalt verdankt, sondern ebenso einer öffentlichen Kultur gegenseitiger Anerkennung. Durchsetzungsschwaches Recht jedoch kann unter Bedingungen asymmetrischer Machtverteilung zum Privileg werden. Recht ist es gemäß demokratischem Verständnis erst dann, wenn es auch für den Schwächsten einklagbar ist und wenn auch für ihn Institutionen bereitstehen, die es durchsetzen.

Das diesem Verständnis zugrundeliegende normative Prinzip der Volkssouveränität wird von Rousseau und Kant mit der Idee des Gesellschaftsvertrags begründet. Menschen ist nur dann zuzumuten, Einschränkungen ihrer Freiheit zu akzeptieren, wenn vorausgesetzt werden kann, dass sie als autonome und vernünftige Wesen entsprechenden Regeln zustimmen können. Aus dem hypothetischen Vertrag lassen sich Legitimitätskriterien politischer Ordnung herleiten, die sich indes nicht nur auf die fiktive Entscheidungssituation beziehen, sondern auch auf den realen Entstehungsprozess der Verfassung. Legitim ist eine gesetzliche Ordnung 
dann, wenn die Adressaten des Rechts effektiv die Möglichkeit haben, an der Gesetzgebung zu partizipieren, also Autoren des Rechts zu sein. In der Idee republikanischer Souveränität ist der Gedanke wegleitend, dass aus der Summe autonomer Willenskundgebungen ein kollektiver Souveränitätsanspruch entsteht, dessen Zweck kein anderer sein kann als der Schutz individueller Autonomieansprüche.

Heute lässt sich Souveränität als Fähigkeit bezeichnen, grundlegende Menschenrechte zu schützen (Müller, 1999a, S. 138). Wenn jedoch die Welt souveräner Staaten vom Untergang bedroht ist und das Menschenrechtsengagement supranationaler Institutionen vom guten Willen mächtiger Akteure abhängt (Habermas, 1998, S. 178), benennt ein so verstandener Souveränitätsbegriff eine Aufgabe, deren globale Lösung aussteht. Vertragstheoretisch lässt sich ein globaler Souverän legitimieren: der Naturzustand, worin Menschen sich gegenseitig Schaden zufügen, ihre Freiheit bedrohen und um knappe Güter streiten, ist territorial nicht eingrenzbar (Kersting, 1996, S. 180 f). Wird unter Souveränität die Macht verstanden, mittels der Errichtung einer Rechtsordnung ein Recht auf die Bedingungen zu garantieren, unter denen gleiche individuelle Autonomie möglich wird, so ist klar, dass sie in einer hochgradig interdependenten Welt nicht mehr ausschließlich den Nationalstaaten zukommen kann.

Ist ein Souverän denkbar, der die hier gestellten Aufgaben zu bewältigen vermag? Als derzeit aussichtsreichster Kandidat kann trotz Demokratiedefizit, mangelnder Durchsetzungsfähigkeit und fehlender Kooperationsbereitschaft globaler Akteure die UNO gelten. Die Literatur, die Vorschläge zur Reform der UNO unterbreitet oder die Heraufkunft einer kosmopolitischen Demokratie beschreibt, ist mittlerweile auf einen beachtlichen Umfang angewachsen. Ihr Motiv ist die Erfahrung, dass Demokratie im Zeitalter der Globalisierung auch im nationalen Rahmen künftig nur dann eine Chance hat, wenn die internationalen Beziehungen demokratisiert werden. Die Überzeugung, der Zweck einer supranationalen Ordnung bestehe im Schutz individueller Rechtsansprüche, stößt in den einschlägigen Publikationen auf breite Zustimmung, wobei negative, aktive und positive Freiheitsrechte unterschiedlich gewichtet werden. Souveränität ist ein Attribut des demokratischen Grundrechts, so formuliert es Held; sie kann von Staaten wie von nicht-staatlichen Gemeinschaften beansprucht werden. Held ist sich der Notwendigkeit einer Macht, die das von ihm postulierte kosmopolitische demokratische Recht nötigenfalls auch gegen den Widerstand mächtiger wirtschaftlicher Interessengruppen zu erzwingen vermag, bewusst, doch zeichnet sich eine solche Macht in seinem dezentralen Modell globaler Demokratie nirgends ab (Held, 1995). Höffe zufolge kann von einer Entmachtung der Staaten gar nicht die Rede sein. Er hält einen gewissen Machtverzicht des Staates im Sinne der Zurücknahme einer Kompetenzanmaßung für geboten. Entsprechend kann dem von ihm geforderten komplementären Weltstaat nur geringe Macht und hinsichtlich ökonomischer Regulierung und gerechter Gestaltung der Sozialordnung allenfalls bescheidene Kompetenz zukommen. Die weltstaatliche Macht muss zwar aus den von Hobbes gelieferten Gründen überragend sein, freilich nur für eng begrenzte Aufgaben (Höffe, 1999).

Wird, wie Habermas argumentiert, Kants Idee eines allen Individuen ungeachtet ihrer nationalen Zugehörigkeit zustehenden Weltbürgerrechts konsequent 
durchdacht, so setzt sie eine als legitim anerkannte, gewaltenteilig organisierte, über das Gewaltmonopol verfügende und mit Sanktionsmacht ausgestattete Weltorganisation voraus (Habermas, 1996a, S. 208-219). Die Einschätzung der Notwendigkeit einer überstaatlichen Politik, die sowohl sicherheits- und elementare menschenrechtspolitische als auch wirtschafts- und sozialpolitische Zwecke verfolgt, hängt von der Einschätzung der Gefährdung innerstaatlicher Demokratie ab. Die Globalisierung geht, wie Cox darlegt, seit den 70er Jahren mit Tendenzen einher, „exzessive“ Demokratie zu limitieren und die Ökonomie aus dem Zuständigkeitsbereich der Politik auszuklammern. Unterwirft sich die Politik den von den globalen Märkten ausgeübten Zwängen, so beschränkt sie sich auf den Streit zwischen Strategien zur Stärkung staatlicher Wettbewerbsfähigkeit. Die Entscheidung für alternative Gesellschaftsmodelle ist dann nicht mehr möglich, womit eine Voraussetzung demokratischer Politik wegfällt (Cox, 1997). Auch Habermas erkennt in der Anpassung an die Imperative des Standortwettbewerbs eine Gefahr. Ihr könnte begegnet werden, wenn es gelänge, jenseits des Nationalstaats Formen demokratischer Politik zu finden. Legitim sind demokratische Staaten nicht nur, weil sie ihren Bürgerinnen und Bürgern gleiche Freiheitsrechte gewähren, sondern auch, weil sie auf die Sicherung von sozialen Lebensbedingungen hinwirken, die allen die gleiche Chance verschaffen, ihre Bürgerrechte zu nutzen. Der regulierende und umverteilende Sozialstaat gehört deshalb zu den Legitimitätsbedingungen der Demokratie. Eine transnationale demokratische Politik müsste folglich die Logik der Standortkonkurrenz durchbrechen, der deregulierten Weltwirtschaft einen politischen Rahmen geben, marktkorrigierend und umverteilend eingreifen. Eine globale Politik, die fähig und bereit wäre, solche Eingriffe vorzunehmen und die extremen sozialen Ungleichgewichte zu beseitigen, liegt freilich für Habermas in weiter Ferne (Habermas, 1998).

Wird unter Demokratie die verfassungsmäßige Herrschaft der Vielen verstanden (Bienen/Rittberger/Wagner, 1998, S. 292), so bestehen derzeit geringe Hoffnungen auf ihre globale Verwirklichung (Imber, 1997; Rosenau, 1998). Trotz ihres unbestreitbaren Demokratiedefizits kommt der UNO diesbezüglich immer noch eine vorrangige Rolle zu; aufgrund ihrer Geschichte ist sie im Gegensatz zu anderen Organisationen wie etwa der im begrenzten Bereich des Handelsrechts ungleich durchsetzungsfähigeren WTO eher fähig, Foren zur Verfügung zu stellen, in denen die Auseinandersetzung zwischen konkurrierenden globalpolitischen Auffassungen möglich ist. Eine tiefgreifende Reform der UNO ist indes, so vermutet ein Kritiker wie Falk, nicht absehbar. Die Aussicht auf eine über die Erweiterung des Sicherheitsrates hinausgehende demokratische Reform wird nicht nur durch das Machtungleichgewicht der Staaten, sondern auch durch den Dissens über das notwendige Ausmaß der Demokratisierung getrübt. Aus der Sicht der dominierenden neoliberalen Wirtschaftsdoktrin ${ }^{15}$ ist ein Ausbau demokratischer

15 Verantwortlich für die Verschärfung globaler Ungleichheiten ist Scholte zufolge nicht die Globalisierung schlechthin, sondern die neoliberale Politik der Globalisierung. „Contemporary globalization has promoted greater unfairness not because of the new geography itself, but mainly because of the accompanying broad policy shift from welfarism to neoliberalism", Scholte, 2000, S. 259. 
Strukturen auf nationaler und internationaler Ebene zumindest dann nicht wünschbar, wenn damit eine stärkere Marktregulierung einhergeht. Doch gerade die Unfähigkeit der UNO, in die Aktivitäten der Finanzmärkte oder der multinationalen Unternehmen regulierend einzugreifen, könnte, wie Falk vermutet, zu ihrer Marginalisierung beitragen (Falk, 1998b).

Das Prinzip staatlicher Souveränität gibt eine Antwort auf die Frage nach der Möglichkeit der Zähmung und breiteren Verteilung der Macht. Das Bedürfnis danach besteht auch auf globaler Ebene, wobei freilich offen bleiben muss, inwiefern die Nutznießer der neoliberalen Globalisierung eine angesichts der globalen Disparität von Macht, Sicherheit und Wohlstand (Hurrell/Woods, 1999) drohende Destabilisierung der Verhältnisse wirklich fürchten. Eine Weltordnung, die mittels Kontrolle und gezieltem Einsatz von Macht ein besseres Funktionieren der globalen Kooperation erwirken würde, kann überdies erst dann als legitim gelten, wenn sie allen Erdenbürgerinnen und -bürgern gleiche Freiheitsrechte, gleiche Partizipationschancen sowie die sozialen Bedingungen garantieren könnte, die erforderlich sind, um diese Rechte und Chancen zu nutzen. Solche Garantien setzen eine Macht voraus, die Aufgaben wie die Friedenssicherung, den Schatz elementarer Rechte für die gesamte Weltbevölkerung einschließlich ihrer schwächsten Mitglieder sowie die Sicherung des öffentlichen Zugangs zu lebenswichtigen Ressourcen zu bewältigen vermag. Wer könnte über diese Macht verfügen wenn nicht ein globaler Souverän in Gestalt einer Weltrepublik?

Soll die politische Philosophie eine Antwort geben auf die Frage, ob die Hoffnung auf die Herausbildung weltrepublikanischer Institutionen begründet ist, gerät sie in Verlegenheit. Sie kann Globalisierungstendenzen interpretieren und auf politisch relevante, Institutionen generierende Prozesse hin prüfen. Sie kann, dem Vorbild Kants (AA, Bd. 7, S. 84 f) folgend, nach „Geschichtszeichen“ forschen, die die Hoffnung auf die Verwirklichung einer Weltrepublik berechtigt erscheinen lassen. Solche Geschichtszeichen machen sich unzweifelhaft bemerkbar; man denke an die weltrepublikanische „Denkungsart“, an den uneigennützigen Enthusiasmus, den viele Zeitgenossinnen und Zeitgenossen bekunden. Dennoch bleibt die Idee globaler Volkssouveränität vorderhand utopisch. Ein Zustand, in dem weltweit gilt, dass die Adressaten des Rechts zugleich dessen Urheber sind, würde tiefgreifende Veränderungen voraussetzen, auf die gegenwärtig nichts hinweist. Nicht der Traum von einem Weltstaat, sondern die Einsicht in die Notwendigkeit, im Interesse globaler Sicherheit Freiheitsrechte gerechter zu verteilen, gibt der Frage, was künftig an die Stelle staatlicher Souveränität treten soll, ihr Gewicht. 